\title{
No es asunto de contar: Espacio íntimo, discurso y subjetividad en He olvidado tu nombre, de Martha Rivera
}

It is not about telling it: Intimacy, subjectivity and discourse in
He olvidado tu nombre, by Martha Rivera

Mariana LiberTad SuÁrez

Universidad Simón Bolívar, Valle de Sarteneja. Venezuela

marisuarez@usb.ve

\section{RESUMEN}

Partiendo de la propuesta de Patrizia Violi (1990) según la cual todo lenguaje contiene una subjetividad y, por tanto, todo acto lingüístico supone la construcción mutua del discurso y del sujeto; y asumiendo -al mismo tiempo- como un rasgo característico de la narrativa de mujeres latinoamericanas de los noventa, la revaluación de la experiencia por encima de las formas de conocimiento más tradicionales de Occidente, se propone una aproximación a la novela He olvidado tu nombre (1997), de la escritora dominicana Martha Rivera, quien genera con su escritura un objeto cultural con implicaciones altamente políticas, como la inscripción del sujeto femenino dentro del mapa cultural del continente, la idoneidad de un espacio discursivo determinado para la permanencia de la subjetividad que la mujer intelectual encarna o, en términos más terminantes, la reflexión acerca de la insuficiencia del lenguaje como herramienta para la construcción de las subjetividades emergentes en el fin del siglo XX.

Palabras claves: Subjetividad femenina, autoescritura, identidad.

\section{ABSTRACT}

Departing from the proposal of Patrizia Violi (1990) according to which, any language contains a subjectivity and, therefore, any linguistic act supposes the mutual construction of the speech and the subject; and taking up office like a characteristic of the narrative of Latin American women of the nineties, the revaluation of the experience over the most traditional forms of Western knowledge, I propose an approximation to the novel He olvidado tu nombre (1997), of the Dominican writer Martha Rivera. Like a cultural 
object with highly political implications, as the inscription of the feminine subject inside the cultural map of the continent, the suitability of a discursive space determined for the permanence of the subjectivity that the intellectual woman personifies or the reflection brings over of the insufficiency of the language as tool for the construction of the emergent subjectivities in the end of the 20th century.

Keywords: Feminine subjectivity, selfwriting, identity.

Recibido: 14-06-2008 Aceptado: 07-10-2008

El erotismo está de moda, solamente tienes que leerte a Gioconda Belli. Tampoco te he visto escribir un poema sobre tu viaje al Pico Duarte. Nunca has escrito nada a la naturaleza.

-No, no se trata de eso. Precisamente: no es asunto de contar, de describir la realidad. Habrá que inventarse una nueva a partir del lenguaje. (Martha Rivera, He olvidado tu nombre)

Z n su artículo "Sujeto lingüístico y sujeto femenino" (1990), Patrizia Violi

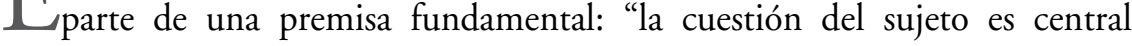
también para la Teoría Lingüística y la Filosofía del Lenguaje. De hecho, no se puede reflexionar sobre el lenguaje sin presuponer al mismo tiempo una teoría, implícita o explícita, del sujeto” (127). Más adelante, en este mismo texto, la autora agrega: "[La experiencia de las mujeres] es también una diferente relación con la emotividad, la fantasía, la imaginación (...) todas ellas formas de 'otros' saberes muy poco interrogados" (Violi, 1990: 138), de lo que podemos deducir como un gesto frecuente dentro de la escritura de mujeres -tanto más de mujeres latinoamericanas, quienes con frecuencia ocupan un espacio discursivo doblemente periférico- la propuesta, dentro de los mismos márgenes de la narración, de una serie de elementos subversivos del sistema lingüístico donde se inscriben.

Si asumimos esta reflexión como punto de partida para la lectura de la novela He olvidado tu nombre (1997), de la escritora dominicana Martha Rivera, tendríamos que la elección de los estilos epistolar y diarístico para estructurar esta obra adquiriría un carácter abiertamente político pues, por una parte, permitiría simular el relato de una vida $-\mathrm{y}$, con ello, produciendo una puerta de acceso a la experiencia de los sujetos femeninos representados en el relato-; y, por la otra, estaría ofreciendo la posibilidad de reflexionar en torno al lenguaje como herramienta de construcción identitaria y-como consecuencia de ello- en torno a la identidad como proceso de simulación. 
No parece ser casual que buena parte de la recepción crítica de la obra sugiera la búsqueda subjetiva de la autora en el texto. Por ejemplo, en una reseña publicada en la revista Atenea, a pocos años de la aparición de He olvidado tu nombre, Renato Fernández Valledor afirma:

Esta obra resulta ser un texto de afirmación existencial en el sentido de la búsqueda del yo. Plantea la lucha por la autenticidad humana y el fundamental encuentro de la persona consigo misma. La trama se centra en las vivencias de dos inseparables amigas, lo cual resulta en una perspectiva femenina y feminista del relato, que sirve de marco al planteamiento de la situación social y cultural de Santo Domingo, de manera muy especial a la transformación ideológica de la intelectualidad dominicana de la posmodernidad (Fernández Valledor, 2000: 158).

Es evidente que este autor le adjudica un carácter épico -en el sentido más tradicional del término- a la narración, dado que como expone en su lectura, el personaje central inicia un recorrido que debe desembocar en un proceso de fundación-que en este caso se encarna en un individuo y no en una colectividad-, y durante el mismo "lucha" con una serie de obstáculos que impiden el hallazgo. Ahora bien, pese a que Fernández Valledor hace alusión directa a la teoría feminista, no parece tener en cuenta al emitir este comentario que en esta novela se pliega una de las estructuras más tradicionales de la literatura occidental: la producción de héroes. Con lo cual, no considera el hecho de que He olvidado tu nombre contiene en su interior una gran cantidad de desplazamientos, remitentes a una puesta en cuestión de la literatura como sistema.

Aunque en un tono mucho menos académico, Sanya Flaviá también se aproxima al texto con una mirada un tanto conservadora. En su evaluación cataloga el texto de "gozada":

por la viva satisfacción que representa terminarla con el convencimiento de haber leído una novela que, al margen de habernos dicho lo que queríamos oír -peccata minuta-, es una novela y no otra cosa. Lúdica: por su humor, casi siempre negro, y la certera combinación de dos estilos narrativos que surten efecto de refrigerio para el lector. Globalizada: por su intención de inventariar la existencia: vida, muerte, amor, amistad, utopías, conflictos, desengaños, pasiones están presentes, a pesar de tratarse de una novela breve, brevísima. Y cosmopolita: por la universalidad en la perspectiva de lo contado (2002).

Pese a que el primer comentario pareciera fijar su atención en el contenido de la novela, mientras que el segundo se centra en el estilo y la estructura, al leerlos queda claro que para los dos críticos se trata de un relato identitario. Es 
decir, las dos aproximaciones sugieren que el fin último de este discurso es la construcción o, cuando menos, la búsqueda de identidad de un sujeto difícil de inscribir en el imaginario que la circunda, lo que trae necesariamente consigo la revaluación de una perspectiva analítica en torno a los sucesos históricos, culturales o sociales que ocurren en el mundo entero.

Sin duda, éste es un elemento fundamental en el texto. Martha Rivera construye a dos subjetividades inconclusas que tratan de erigir un lugar de enunciación desde donde ingresar al espacio público; no obstante, más allá -o, quizás a propósito- de la perspectiva evaluadora de estos sujetos, en esta novela se tematizan las estrategias empleadas por los personajes periféricos para dialogar con el poder, al tiempo que se reflexiona en torno a la capacidad y/o posibilidad de resistencia de las mujeres intelectuales para generar un discurso propio. En otras palabras, más allá de la adscripción de un sujeto dentro de un imaginario, esta narración se centra en la revisión de las estrategias de figuración empleadas -de manera más o menos afortunadas- por las dos subjetividades principales de la historia.

La novela cuenta la vida de dos mujeres de nombre desconocido. Se estructura a partir de unos textos que, en principio, simulan ser cartas, para luego tomar forma de diario y, finalmente, ser presentados como partes de un "libro de vida" que rinde culto a una mujer recién fallecida. Son relatos breves de diferentes episodios de la vida de esta mujer, recogidos y, eventualmente, glosados por una narradora -amiga cercana de la protagonista-, quien sobrevive para organizar los recuerdos. Dentro del texto, cada episodio es presentado por una voz confesional y (re)presentado por otro sujeto que ha sido testigo de las experiencias de vida de la protagonista.

El hecho simple del contrapunteo, aunado a la circunstancia de que no se trate propiamente de un diario de vida, sino de una novela que simula serlo, llevan a pensar esta obra como una propuesta textual que, por un lado, alienta a la subversión del lenguaje y, por otro, erige el resultado de esta subversión como un modo de acceder a la experiencia. Se trata de una obra que dialoga con diversas tradiciones desde su misma estructura, pues al mismo tiempo que se encarga de repasar una serie de géneros literarios tradicionalmente entendidos como subliterarios, tematiza y reflexiona sobre la relación del sujeto femenino con los mismos.

$\mathrm{Al}$ respecto, es importante tener en cuenta que, dentro de los estudios literarios de finales del siglo XIX y comienzos del XX, las autobiografías, los epistolarios y los diarios de vida fueron entendidos como textos legitimadores y legitimantes por/de la autoridad de un individuo. Ahora bien, el hecho simple de saber que en este caso no se trata de escrituras caóticas, espontáneas 
o personales, sino de un simulacro editado y/u organizado por un personaje definido, quien pareciera - dicho sea de paso- autoescribirse en estas páginas, permite comprender las escrituras autorreferenciales como textualidades heterogéneas que, dada su condición, contienen en su interior múltiples discursos, reflexiones y referencias.

En otras palabras, este discurso propone en su interior que no es más ni menos auténtico que otras obras diarísticas o epistolares, dado que, al igual que ocurre en todos los casos, la función primordial del texto es generar un lugar subjetivo desde donde percibir el entorno y reescribirlo. Por tanto, esta novela constituirá una lectura de la Historia contemporánea de República Dominicana, desde la postura de un personaje profundamente paradójico, que relaciona el discurso intimista con el espacio público y, desde ahí, convierte una experiencia singular en un discurso político.

El punto de partida de la anécdota relatada en la novela es la década de los setenta, cuando "Los verdaderos hippies comenzaban a ser parte de la historia, pero los dominicanos siempre hemos llegado un poco tarde" (Rivera, 1997: 23). Ahí se cuentan dos sucesos personales, el fallecimiento del padre de la protagonista y el de un amigo cercano. A diferencia de los diarios y los epistolarios más tradicionales, esta novela no inicia su anécdota con el nacimiento del héroe, ni con la reconstrucción de los detalles de la infancia de la protagonista, sino que parte de un desprendimiento, de una ausencia, de una muerte.

Este comienzo a partir de la negatividad permite pensar varios hechos. Por un lado, el sujeto femenino que protagoniza esta historia no presenta un recorrido prospectivo, sino cíclico: comienza a ser narrada desde un fallecimiento y acaba en otro; en segundo lugar, la muerte que le da origen no es una muerte cualquiera, sino de la "muerte del padre", es decir, la muerte de esa figura que ha encarnado tradicionalmente, dentro del imaginario occidental, el lugar de autoridad, las marcas de identidad y el nombre; finalmente, esta pérdida, si bien provoca un viaje épico -confesado abiertamente por la voz narrativa-, no es uno que desemboque en la creación de un hombre nuevo, sino - una vez más- en la dilución de una identidad:

¿Cuántas veces me he preguntado quién soy realmente? ¿En qué momento comencé a convertirme en este pensamiento que vive por sí mismo, sin la necesidad de tu impulso?

¿Cuándo dejé de ser una niña nocturna que se sentaba en el escalón del baño, frente a la puerta del cuarto de mis padres, esperando a que mi madre sintiera la fuerza de mi llamada y saliera con su pijama de nylon a recogerme del miedo, para acostarse conmigo y que yo al fin durmiera? Todo comenzó cuando escuché por primera vez hablar de la muerte (Rivera, 1997: 34). 
Estas interrogantes que aparecen en las primeras páginas del texto van a determinar la búsqueda fundamental que soporta la escritura. Ahora bien, más allá de un recorrido para encontrarse a sí misma, este personaje se exhibe e interpela a quienes la rodean para que ellos traten de definir su ser desde sus propios discursos. Quizás por eso mismo la novela -en lugar de proponer una serie de confesiones que lleven a discusión el "yo" de los personajes centrales: la mujer narradora y la mujer narrada-, está compuesta de historias breves, sin héroe determinado que -contrastadas con los discursos de autores, músicos o pintores reconocidos por la alta cultura, cuyas escrituras son manejadas a manera de referencias intertextuales- funcionarán como una suerte de rearticulación de la perspectiva como elemento fundamental de la Historia.

En esta obra se hacen referencias a la caída del muro de Berlín, a la Perestroika, o al período especial cubano, como hechos susceptibles de ser intervenidos por cualquier sujeto. Como verdades universalizadas que al ser (re)contadas, permiten juzgar una serie de categorías fundamentales en la literatura latinoamericana de fin de siglo XX: la posibilidad y la capacidad de escritura de los sujetos conscientemente ubicados en la periferia, "el intelectual" y "la intelectualidad" como nociones posibles, la existencia o no de la sensibilidad posmoderna. Por ello, no sería arriesgado afirmar que se trata de una novela que emula la escritura confesional para emplear la arbitrariedad de la memoria y la discontinuidad narrativa como espacios para el debate teórico.

A esto se suma otra serie de particularidades de la obra que hacen pensar en este límite difuso entre la teorización y la narración. Una de las claves que permite revisar este hecho es que dentro de la misma novela se encuentran el tono homogéneo e, inclusive, didáctico y/o informativo que le imprime la autora del libro construido en la metaficción, frente a los recuerdos caóticos y fragmentados de la protagonista. La voz que "lee y escribe" a su amiga moribunda, se detiene en muchas ocasiones dentro del registro de la prosa conceptual y trata de entender -o quizás, aunque no lo confiese, de explicar- esa subjetividad femenina condenada a desaparecer del imaginario dominicano. Por ejemplo, ante una carta de amor donde la protagonista del relato comenta:

A mí empezó a quillárseme la nota con sus comentarios, cuando me dijo "no te vuelvas a alejar hacia la playa, estás muy arrebatada y te puedes ahogar". Entonces, Juan Alberto vino en mi defensa diciéndole: "Lo que pasa es que ella está en hongos de verdad. Déjala tranquila, la gente en hongos nunca se ahoga, sobre todo si no sabe nadar". De pronto Frank dijo: "está lloviendo", y yo contesté "es la risa de Martín". Así lo amaba. Así lo amo hoy, cuando he dejado de amarlo (Rivera, 1997: 64). 
El personaje femenino que asume el lugar de la (autor)idad repone:

La relación con Martín empezó a deteriorarse, en la misma medida en que tú te encargabas cada vez más a una vida dispersa: la universidad abandonada indefinidamente, negligencias en los estudios y en la militancia política y ahora una nueva pasión: hacer cerámica. Compraste todos los materiales y un horno, donde quemabas aquellas piezas extrañísimas que moldeabas creyéndote escultora. Finalmente, abriste unas clases para niños en las tardes, en el patio de la casa de tu mamá, donde los enseñabas a hacer hojas, flores y muñequillas (Rivera, 1997:65).

El contraste entre los dos registros, aunque parezca evidente, se diluye gracias al impulso comunicativo de ambas expresiones. Impulso que se evidencia a lo largo de toda la novela, aun cuando en el simulacro propuesto dentro de la misma, uno de los textos haya sido escrito para ser publicado y el otro no. A partir de entonces, el supuesto privilegio a la experiencia que se da en aquellos fragmentos del relato donde la voz narrativa es asumida por la mujer moribunda, no es sostenible sin el afán teorizador de la segunda voz del texto, esa encargada de "traducir" en materia novelesca los indecibles. O bien, en el mejor de los casos, de reconocer que aquello que se desea comunicar no es materia cifrable en lenguaje.

Entonces, aun cuando -a simple vista- podría afirmarse que la novela formula un modelo estrictamente autorreferencial -pues más allá de los acontecimientos históricos, reseña la articulación de los mismos desde la perspectiva de un personaje y sólo después de hacerlo, incluye la reproducción y/o explicación de este proceso de lectura por parte de otro-, queda claro que la obra tiende más al cuestionamiento que a la fundación. En otras palabras, con su estructura narrativa, He olvidado tu nombre consigue poner en tela de juicio la posibilidad de una escritura única y referencial, al tiempo que apuesta por la intertextualidad y la glosa como únicas formas de expresión existentes.

Este hecho, en apariencia simple, remite de inmediato a la figura del autor y, desde ahí, inicia un debate en torno a la identidad del intelectual latinoamericano ¿Es posible que exista la propiedad, el ejercicio de poder y la voluntad de representación si todos los discursos son lecturas o reconstrucciones de discursos anteriores? ¿Esta mujer narradora topicalizada en la historia tiene posibilidades reales de producir un bien de consumo e intercambiarlo? ¿Su papel es más de recepción que de producción? ¿Hay una fórmula más o menos veraz para el relato de la experiencia?

Sin duda, la elección y la reconstrucción de tipologías textuales como el diario íntimo, la carta o la autobiografía sirven en esta novela no sólo para cuestionar a los géneros en sí, sino además para revisar todos los discursos occidentales, 
propiamente latinoamericanos, y eventualmente dominicanos, que asocian estos productos lingüísticos con una subjetividad determinada. Es decir, en el momento mismo en que se reevalúan los géneros, caen bajo sospecha el espacio privado, la intimidad y otras tantas categorías que han marcado dentro de la tradición occidental la presencia de las mujeres intelectuales en el imaginario.

Quizás por eso mismo, el afán de descubrir, iluminar o educar que motiva a la protagonista en las primeras líneas de la novela a convertirse en escritora, progresivamente va desapareciendo, pues, si bien, el lenguaje es entendido en el texto como herramienta recuperadora de la existencia perdida, al mismo tiempo se reafirma como un instrumento coercitivo, que limita las relaciones humanas y le niega existencia a las experiencias inenarrables. De aquí que el personaje central renuncie a su autoría y, de manera paulatina, permita que su historia sea narrada por otr(a):

A pesar de todo lo que vendrá, a pesar de una taza de café que no bebí para ser buena, a pesar de que el no definitivo tembló siempre en la punta de los labios, como una bala ebria que duda antes de penetrar ese dios que llamamos Corazón, a pesar de que tú y yo respirábamos el final, y torpemente excusábamos a los días asombrosos, que pasaban por nuestra historia llenos de magia; a pesar de que nos une algo más feliz que la tristeza de perdernos, hemos conquistado lo que la gente buscará en la eternidad. El lenguaje que prescinde de los símbolos, la página inconclusa, lo que pudimos ser pero no fuimos, letras de un alfabeto de cristal que corta el hielo, todo eso quedará fuera del tiempo y del espacio. Esta tarde voy a enjaular la lluvia en nuestro abrazo (Rivera, 1997: 76).

No hay posibilidad alguna en medio de este discurso de concebir a la protagonista-autora de las cartas, como individualidad. Las palabras que ella enuncia son dependientes de muchos otros discursos y sólo se tornan legibles si el otro personaje femenino -que asume el poder de la palabra-interviene en la construcción del relato, para reinscribirlo en un texto mayor. Las dos visiones de la historia cabalgan una sobre la otra, lo que trae como consecuencia un replanteamiento del tema del poder y de las jerarquías de género, sociales y culturales, al momento de iniciar el proceso de construcción de ese "yo" sin nombre.

A este respecto, no dejan de ser interesantes las identificaciones que realiza el personaje principal con los intelectuales, músicos, escritores, actores o, lo que es lo mismo, con productores de sentido legitimados y reconocidos por el imaginario dominicano de cada uno de los momentos históricos que reconstruye. La voz confesional comienza refiriendo a Alejandro Dumas como discurso rector de la infancia y pasa luego a mencionar a Pablo Neruda; 
también expone que a partir del año 1978 -cuando comienza la llamada era democrática- consume libros budistas e investigaciones sobre extraterrestres; en la década de los noventa, por influencia de uno de sus novios, comienza a leer a Alejandra Pizarnik y a otros poetas suicidas; para, finalmente, abandonar sus libros porque al único hombre con quien contrae matrimonio - de quien se separa poco antes de morir- no le gustaban. No deja de resultar interesante que esta última referencia no aparezca en boca del personaje protagónico, sino del otro personaje que narra.

El tránsito de obras literarias con un carácter fundador, con un lenguaje cuidado, respetuosas de las normas de escritura, a textos de contenidos menos tradicionales -aunque, en esta etapa no se menciona la forma-, y que permiten -a su vez- el tránsito a estéticas más excéntricas para, finalmente, acabar en la ausencia total de la palabra escrita, bien puede funcionar como un espejo literario, donde se indica la ruta subjetiva que asume el personaje narrado. Ello permite deducir que la construcción de la protagonista como subjetividad está directamente asociada a su intervención de y por otros discursos que, a su vez, contienen otras subjetividades.

A propósito de ello, vale la pena recordar, como uno de los rasgos definidores de los textos autobiográficos decimonónicos, "la escena de la lectura". Era frecuente que los narradores y protagonistas de memorias a lo largo del siglo XIX buscaran en diaristas o intelectuales consagrados un espacio de legitimación que les permitiera erigirse como voces autorizadas. Sin duda, éste parece ser uno de los elementos emulados en la obra de Martha Rivera; sin embargo, en medio del simulacro que supone la escritura de He olvidado tu nombre, este proceso de asociación es sustituido por una elección voluntaria de referentes que apunten hacia la desaparición de un significante estable.

Más que para autorizar el relato de su experiencia, este personaje emplea las referencias a otras escrituras como una forma de indicar su desaparición y la imposibilidad de narrar el "yo", sin reducirlo a discurso puro. No es casual que este personaje que en principio desea erigirse como intelectual -al menos en el sentido más tradicional del término- acabe en la desintegración y, más que nada, que sólo subsista - una vez que ha fallecido- en la interpretación de otro sujeto letrado que se ve en la necesidad de organizar su discurso.

La carta que la protagonista dirige al padre de un novio que nunca conoció es tal vez el último intento de asir su subjetividad en la palabra escrita, por ello, no deja de ser llamativo que dentro del texto afirme:

Demasiadas palabras, rojas como la sangre, silenciaron su silencio en la piel de mi nuca. Usted, designio de los Dioses, pájaro breve e indefenso que fue dejando sus trinos en mis manos abiertas, y que calentó con su aliento 
escritural y sagrado la cera (Dédalo respirando en mi espalda, donde las mariposas mutilaban sus alas, para que yo no pudiera elevarme a la luna gélida que no quiso mirarnos) cuando pactamos sonidos que ahuyentaron el humo. Sí. Tal vez al poema sólo le queda el silencio. Quizás mi tren se detuvo en su estación rabiosa, con más rabia que el verso. Y tal vez agradezca a mi memoria que palidece poco a poco, tocar con vértigo de carne y de letra este leve epitafio, donde la palabra que rueda y que cae para no levantarse, abre sus labios tibios, asesinando el recuerdo de lo que usted y yo inventamos sin saberlo (Rivera, 1997: 89).

A esta inestabilidad subjetiva se suma un desequilibrio permanente de los roles sexuales que hay en la novela, una ruptura recurrente del dualismo hombre/ mujer, por medio del cual se sugiere -en la glosa mutua entre discurso analítico y el puramente narrativo, basado en la experiencia- un desprendimiento terminante de las relaciones tradicionales entre el cuerpo y la identidad sexual. El género y las conductas que se encuentren marcadas por esta categoría dentro de la novela serán mostrados como otras de las tantas elecciones puras y simples de una vía de adscripción al espacio público.

En otras palabras, el cuerpo sexuado se convertirá dentro de esta obra en un lugar donde se acumula tanto la experiencia individual de la mujer narrada, como el proceso de lectura que de ella hace la mujer narradora. A partir de esta concepción, el personaje tendrá la capacidad de iniciar su propio proceso de formación y de deformación identitaria sin que necesariamente medie la narración. A medida que avanza la obra, el cuestionamiento de la polaridad hombre/mujer se traslada hacia otras dicotomías propias del pensamiento occidental directamente asociadas: emotividad/racionalidad, animalidad/ humanidad, privado/público:

Contigo descubrí que dos cuerpos pueden ser también dos espejos que imaginan lo que miran. Por eso te eternizo esta noche en un rayo de luz que va dejándote plasmada en toda superficie, incluida la del poema. Perdóname por no haber podido amarte como lo necesitabas, pero la vida nos fue modelando a las dos de diferente manera. Gracias por tu alma, por ese ser que fuiste: pequeño mar que nunca conoció el mar. La gente no debería tener sexo. Todos deberíamos ser al mismo tiempo hombres y mujeres... ángeles (Rivera, 1997: 117).

Ciertamente, tanto los encuentros intersubjetivos como el ingreso al espacio de las letras resultan indispensables para generar una individualidad de la protagonista, de hecho, estos dos elementos van a definir la edificación de una memoria que permita identificar el momento de enunciación del personaje que cuenta como el presente. Quizás por ello, en medio de sus glosas a la experiencia 
de la protagonista, la narradora rescate sólo los elementos que pueden ingresar -aunque, eventualmente, provocando algún ruido- a la historia continua y lineal que constituye la novela y, simultáneamente, el personaje moribundo reitere que sólo el olvido es capaz de sostener su identidad.

Precisamente, el final de la novela vuelve sobre la reflexión en torno a la posibilidad de ser, para la mujer intelectual en el imaginario latinoamericano del siglo XX. En el sexto capítulo de la obra, se había relatado detalladamente cómo la protagonista se había practicado un aborto en "un lugar mugriento", que casi le costó la vida y que la dejó inhabilitada para tener hijos por siempre. La nostalgia por el fallecimiento de Rubaiyat, la hija no nacida a quien la protagonista le dedica cartas, pensamientos y acciones, es otra de las recurrencias que llenan de sentido la novela.

No parece ser casual que en el último capítulo del texto, cuando la protagonista ya ha decido su muerte física, se encuentre con un hijo -o con un muchacho que hubiera podido serlo- y comience a seducirlo. La condición de maternidad, reñida en sus comienzos con el carácter irracional atribuido a la reproducción física de cualquier especie, no puede ser asociada a la supervivencia de la mujer intelectual, tanto menos, de la intelectual latinoamericana. Quizás por eso, la renuncia a la palabra escrita abre esta posibilidad de intercambio que genera un último texto en la voz narrativa:

¿Sabes José, hijo, que Rubaiyat hoy tendría tu edad? Pero ella también, como nuestro deseo, se quedó sepultada en mi vientre (tumba que no profanaste). Donde quiera que estés, pequeño, oye la voz de mi amor incestuoso. Siénteme suavemente lamiendo tu cuello tan terso. Siente tu lengua haciendo agua mi boca en tu boca de agua, y tócate, como estoy segura tuviste que tocarte ésa, mi última noche despierta. Piensa que soy yo, tu madre, quien se bebe la última noche despierta. Piensa que soy yo, tu madre, quien se bebe la espuma derramada en tus dedos. Piensa que ahora, cerca de mi final, que es tu principio, eres el único hijo que tuve, que tengo, que tendré (Rivera, 1997: 133).

Este proceso de seducción acaba por cancelar cualquier vínculo con "el nombre del padre" que pudiera percibirse en el discurso, pues el incesto, la reiteración de la maternidad como condición deseable para una mujer y el posterior sacrificio de la protagonista, generan ese efecto subversivo que esta "mujer intelectual" intentó crear en la escritura y que el lenguaje le impidió expresar. Así pues, las acciones desestabilizadoras no sólo abren la opción de criticar los modelos normativos de sexualidad, sino que además, (autor)izan la puesta en circulación de este discurso aplazado por décadas y, por tanto, de la subjetividad subyacente al mismo. Desplazarse hasta el espacio de los 
indecibles le permite a la protagonista la creación de nuevas alternativas y espacios de subjetivación que se resisten a acoplarse a la administración de los placeres propuesta en la República Dominicana de finales del siglo XX o, como diría la voz narrativa, hacer "tu propia vida (...) el más hermoso poema”.

\section{REFERENCIAS}

Fernández Valledor, Renato. 2000. "Reseña: He olvidado tu nombre, de Martha Rivera", en Atenea. Revista bilingüe de las humanidades y las ciencias sociales. Vol. XX, pp. 157-164.

Flaviá, Sanya. 2002. "He olvidado tu nombre", en Cielonaranja, página de Martha Rivera: http://www.cielonaranja.com/rivera.htm. Consulta, septiembre de 2007. Rivera, Martha. 1997. He olvidado tu nombre. Santo Domingo. Casa del teatro.

Violi, Patrizia. 1990. "Sujeto lingüístico y sujeto femenino", en Colaizzi, Giulia (ed.) Feminismo y teoría del discurso. Madrid: Cátedra, pp. 127-142. 